\title{
INHIBITORY EFFECT OF SAPONINS AND POLYSACCHARIDES FROM RADIX RANUNCULI TERNATI ON HUMAN GASTRIC CANCER BGC823 CELLS
}

\author{
Lidan Niu ${ }^{1}$ ， Yingfeng Zhou ${ }^{1}$ ， Bing Sun ${ }^{1}$ ， Junling $\mathrm{Hu}^{1}$ ， Lingyu Kong ${ }^{1}$ ， Sufang Duan $^{2 *}$ \\ ${ }^{1}$ The First Affiliated Hospital of Xinxiang Medical University \\ ${ }^{2}$ The Third Affiliated Hospital of Xinxiang Medical University \\ *E-mail: duansufang88@163.com
}

\begin{abstract}
The effects of different Radix ranunculi ternati extracts on human gastric cancer BGC823 cells were investigated, different methods were used to extract the saponins and polysaccharides from Radix ranunculi ternati, and MTT assay and colony formation assay were used to observe the effects of saponins and polysaccharides from Radix ranunculi ternati on in-vitro cultured human gastric cancer BGC823 cells. The results found that the saponins and polysaccharides from Radix Ranunculi Ternati had certain effects on both the growth and colony formation of human gastric cancer BGC823 cells, while improving the immune function of normal mice, of which saponins had more significant effects than polysaccharides.
\end{abstract}

Key words: Radix Ranunculi Ternati, saponin, polysaccharide, human gastric cancer BGC823 cells

\section{Introduction}

Radix ranunculi ternati is the root tuber of Ranunculus ternatus Thunb., which belongs to the Ranunculaceae family. It is named for its fleshy, clustered, fusiform root tuber, yellowish-brown rind, and cat claw like shape. It is sweet and pungent in taste, warm in nature; it enters the liver and lung meridians; and has the effects of resolving phlegm, dissipating nodulation, removing toxicity and subsiding swelling; it is mainly used in the treatment of scrofula, phlegm nodule, furunculosis, snake and insect bites, and other diseases (Chinese Pharmacopoeia Commission, 2010; Yin et al., 1993). It is reported in the literature that the Radix Ranunculi Ternati has a good effect on malignancies such as breast cancer (Yin et al., 2008).; it also has a certain effect on colon cancer (Zhou et al., 2009). Radix Ranunculi Ternati has complex chemical composition; its main constituents include saccharides, organic acids, sterols and esters, volatile oils, amino acids, flavonoids and glycosides, alkaloid glycosides, etc.

\section{Materials and Methods}

Medicinal Materials

Radix Ranunculi Ternati, (voucher No km-2012-67) grown in Xinyang, Henan, purchased from Xinxiang Pharmaceutical Company.

\section{Instruments}

Olympus inverted microscope (OLYMPUS, Japan), low temperature refrigerated centrifuge (Eppendorf, Germany), clean bench (Suzhou Purification Equipment Co., Ltd.), $\mathrm{CO}_{2}$ incubator (SANYO, Japan), continuous wavelength microplate reader (Bio-RAD).

\section{Reagents}

RPMI1640 medium (GIBCO, USA), 0.25\% trypsin (Sigma, USA), MTT (Sigma, USA), fetal bovine serum 
(Hangzhou Sijiqing Biological Engineering Materials Co., Ltd.), other reagents were all of analytical grade.

\section{Cell Lines}

Human gastric cancer cells BGC823 were provided by the Affiliated Hospital of Xinxiang Medical University.

\section{Preparation of saponin extract from Radix ranunculi ternati}

Referring to the methods in (Wang et al., 2004; Liu et al., 2007), $100 \mathrm{~g}$ of dried Radix ranunculi ternati was crushed into coarse powders, put in a Soxhlet extractor, and extracted with 95\% ethanol for $6 \mathrm{~h}$, ethanol was recovered from the alcohol extract, and the resulting solution was extracted twice with diethyl ether, and then extracted three times with water saturated n-butanol, the n-butanol extract was extracted twice with $0.1 \mathrm{~mol} / \mathrm{L}$ sodium hydroxide, $\mathrm{n}$-butanol solution was recovered, followed by drying, and Radix Ranunculi Ternati total saponins were obtained. The total saponins were dissolved in water, and prepared as $1 \mathrm{~g}$ crude drug/mL, then filtration sterilized, and stored at $4^{\circ} \mathrm{C}$ for later use.

Preparation of polysaccharide extract from Radix ranunculi ternate

Referring to the method in (Twentyman, 1987), $100 \mathrm{~g}$ of dried Radix ranunculi ternati was crushed, and ultrasonically extracted three times with ethanol as the solvent, and with the extraction time of 20 min each, ultrasonic power of $300 \mathrm{w}$, then the filtrates were combined, and ethanol was recovered, followed by drying. The polysaccharides were dissolved in water, and prepared as $1 \mathrm{~g}$ crude $\mathrm{drug} / \mathrm{mL}$, then filtration sterilized, and stored at $4^{\circ} \mathrm{C}$ for later use.

\section{Determination of cell proliferation inhibition rate by MTT assay (Svegliati et al., 1999)}

Poorly differentiated human gastric adenocarcinoma BGC823 cells in the logarithmic growth phase were collected, and diluted to a concentration of about $5 \times 10^{4} / \mathrm{ml}$ with culture medium, seeded in 96 -well plate, and cultured for $24 \mathrm{~h}$, then the culture medium was discarded, and the drug-containing medium was added (triplicate wells for each concentration group), meanwhile, blank control group which was added with complete medium only was set up, after placing in a $37^{\circ} \mathrm{C}, 5 \% \mathrm{CO}_{2}$, saturated humidity incubator and incubated for $48 \mathrm{~h}$, each well was added with $20 \mu \mathrm{L}$ of MTT solution, the incubation was continued for another $4 \mathrm{~h}$, then the supernatant was discarded, each well was added with $150 \mu \mathrm{L}$ of DMSO, and shaken with a micro mixer for $10 \mathrm{~min}$, after the crystals were fully dissolved, OD values were measured at a wavelength of $570 \mathrm{~nm}$ using a microplate reader, and the tumor cell proliferation inhibition rate was calculated according to the following formula:

Inhibition rate $(\%)=(1-$ OD value of experimental group / OD value of control group $) \times 100 \%$

Colony forming assay (Zhang., 2004; Zhang et al., 2005)

Poorly differentiated human gastric adenocarcinoma BGC823 cells in the logarithmic growth phase were collected, and seeded in 24-well plates at the density of 100 living cells/well, cultured for $24 \mathrm{~h}$, then added with different concentrations of drugs (triplicate wells for each concentration group), meanwhile, blank control group which was added with complete medium only was set up. After the cells were incubated in a $37^{\circ} \mathrm{C}, 5 \% \mathrm{CO}_{2}$, saturated humidity incubator for $10 \mathrm{~d}$, the supernatant was discarded, then the cells were fixed in $95 \%$ ethanol, and crystal violet stained. Colonies containing more than 50 cells were counted under a microscope, and colony formation inhibition rate was calculated according to the following formula: Colony formation inhibition rate $(\%)=(1-\mathrm{CFU}$ number of experimental group / CFU number of control group $) \times$ $100 \%$ 
Effect of saponins and polysaccharides from Radix Ranunculi Ternati on immune function of normal mice (Pang et al., 2001)

The mice were randomly divided into blank control group, saponin group and polysaccharide group, with 10 mice in each group, after continuous intragastric administration for $14 \mathrm{~d}$, immune function was determined.

\section{Lymphocyte transformation test}

Spleen cells were collected under sterile conditions, minced and ground, centrifuged at $1000 \mathrm{r} / \mathrm{min}$ twice for $10 \mathrm{~min}$ each time, then cell concentration was adjusted to $1.5 \times 10^{6} / \mathrm{ml}$ with culture medium, triplicate wells were set up for each experimental group, with the final volume for each well $100 \mu \mathrm{l}, 100 \mu \mathrm{l}$ of saponins and polysaccharides were added, while in the blank control group, only the culture medium was added, after culturing for $72 \mathrm{~h}$, OD value was measured at 540nm, and stimulation index (SI) was calculated: SI = OD value of test well or negative control well / OD value of blank control well.

Spleen index: Spleen index $=$ spleen mass $(\mathrm{mg}) /$ body mass $(\mathrm{g})$.

Determination of natural killer (NK) cell activity (Zhou et al., 1995)

The volume fraction of spleen cells was $1.5 \times 10^{6} / \mathrm{ml}$, and the volume fraction of the target cell BGC $8235 \times 10^{5} / \mathrm{ml}$, control wells were $0.1 \mathrm{ml}$ of effector cells and $0.1 \mathrm{ml}$ of culture medium; $0.1 \mathrm{ml}$ of target cell solution and $0.1 \mathrm{ml}$ of culture medium respectively. Experimental wells were $0.1 \mathrm{ml}$ of effector cell solution and $0.1 \mathrm{ml}$ of target cell solution, after incubating at $37^{\circ} \mathrm{C}$ for $2 \mathrm{~h}$, the effector-target reaction was stopped, followed by centrifugation at $1500 \mathrm{r} / \mathrm{min}$ for $5 \mathrm{~min}$, after that, $100 \mu \mathrm{L}$ of supernatant was added to each well of 96 -well plate, preheated at $37^{\circ} \mathrm{C}$, and $100 \mu \mathrm{L}$ of substrate solution was added to each well, allowed to stand at room temperature for $10 \mathrm{~min}$, then $30 \mu \mathrm{L}$ of $0.1 \mathrm{~mol} / \mathrm{L}$ citric acid was added to stop the enzymatic reaction. OD value at $570 \mathrm{~nm}$ was measured, and NK cell activity was calculated: NK cell activity $(\%)=[1-$ OD value of experimental well / (effector cell + culture medium) OD + (target cell + culture medium) OD)] $\times 100$.

\section{Results}

Effects of different concentrations of saponin and polysaccharide extracts from Radix Ranunculi Ternati on human gastric cancer BGC823 cells

The results showed that the five dose groups of saponins and polysaccharides all had inhibitory actions on the growth of human gastric cancer BGC823 cells. The Radix ranunculi ternati saponins significantly inhibited human gastric cancer BGC823 cells, and the effect was enhanced with the increase of concentration, which was in a concentration-dependent manner. The polysaccharide dose group, although exhibited significant difference when compared with the control group, had a less effective tumor inhibitory effect than saponins.

Effects of saponins and polysaccharides from Radix Ranunculi Ternati on colony formation of human gastric cancer BGC823 cells

Under different concentrations, the experimental groups all showed statistically significant differences $(\mathrm{P}<0.05)$ when compared with the control group. The effect of Radix Ranunculi Ternati polysaccharides on colony formation of human 
gastric cancer BGC823 cells was concentration dependent, with the increase of concentration, colony formation inhibition rates were $32.64 \%, 55.62 \%$, and $100 \%$ respectively. No colony formation was observed for the Radix Ranunculi Ternati saponins within the concentration range; visual analysis showed that the Radix Ranunculi Ternati saponins had stronger colony formation inhibitory effect on human gastric cancer BGC823 cells than the Radix Ranunculi Ternati polysaccharides.

Table 1: Effects of Radix Ranunculi Ternati saponins and polysaccharides on inhibition of human gastric cancer BGC823 cells (\%)

\begin{tabular}{|ccc}
\hline $\begin{array}{c}\text { Drug concentration } \\
(\mu \mathrm{g} / \mathrm{ml})\end{array}$ & Inhibition rate $(\%)$ & \\
6.25 & $24.52^{* *}$ & Polysaccharides \\
12.5 & $33.76^{* *}$ & $3.75^{*}$ \\
25 & $49.11^{* *}$ & $5.12^{*}$ \\
50 & $68.65^{* *}$ & $14.98^{* *}$ \\
100 & $92.53^{* *}$ & $30.47^{* *}$ \\
\hline
\end{tabular}

Comparison with the control group, $* \mathrm{P}<0.05, * * \mathrm{P}<0.01$

Table 2: Effects of saponins and polysaccharides from Radix Ranunculi Ternati on colony formation of human gastric cancer BGC823 cells $(\bar{X} \pm \mathrm{S}, \mathrm{n}=3)$

\begin{tabular}{lclc}
\hline \multicolumn{1}{c}{ Group } & Concentration $(\mu \mathrm{g} / \mathrm{mL})$ & CFU number & $\begin{array}{c}\text { Colony formation } \\
\text { inhibition rate }(\%)\end{array}$ \\
\hline Blank control group & 12.5 & $89.24 \pm 1.63$ & 100 \\
& 25 & $0^{* *}$ & 100 \\
Saponin group & 50 & $0^{* *}$ & 100 \\
& 12.5 & $0^{* *}$ & 32.64 \\
Polysaccharide group & 25 & $60.12 \pm 2.45^{* *}$ & 55.62 \\
& 50 & $39.54 \pm 1.23^{* *}$ & 100 \\
\hline
\end{tabular}

Comparison with the blank control group, ${ }^{*} \mathrm{P}<0.05,{ }^{* *} \mathrm{P}<0.01$

\section{Effects on immune function of normal mice}

It can be seen from the results that the different concentrations of Radix ranunculi ternati saponins and polysaccharides can all significantly improve the spleen index and tumor cell killing rate of NK cells in normal mice. Of which the Radix ranunculi ternati saponins had a more pronounced effect, it exerts its anti-tumor effect by improving immune function, thus promoting the growth of normal cells.

\section{Discussion}

Many literatures have reported the anti-tumor effect of Radix Ranunculi Ternati. Radix Ranunculi Ternati is also clinically applied to treat tumors, with respect to the anti-tumor mechanism of Radix Ranunculi Ternati, literature has found that the Radix Ranunculi Ternati can induce the production of tumor necrosis factor (TNF), after taking it, the body's own TNF secretion levels can be elevated, thereby treating and immunizing against the tumors (Nicotera et al., 1998). Another 
study has found that the anti-tumor effect of Radix Ranunculi Ternati may be associated with the increase of $\mathrm{Ca}^{2+}(\mathrm{Szende} \mathrm{et}$ al., 1990), elevated intracellular calcium plays a decisive role in apoptosis (Szende et al., 1990), and in experiments, after the cells were affected by the Radix Ranunculi Ternati saponins, $\mathrm{Ca}^{2+}$ was significantly increased.

Table 3: Effects of Radix ranunculi ternati on immune function of normal mice $(\bar{X} \pm S)$

\begin{tabular}{ccccc}
\hline Group & $\begin{array}{c}\text { Dose } \\
(\mathrm{g} \text { crude drug/kg) }\end{array}$ & Spleen index & SI & $\begin{array}{c}\text { NK cell killing } \\
\text { rate }(\%)\end{array}$ \\
\hline Blank control group & 3 & $4.3 \pm 0.8$ & $1.21 \pm 0.14$ & $29.20 \pm 4.84$ \\
& 6 & $4.9 \pm 1.3$ & $1.29 \pm 0.21$ & $40.58 \pm 6.57$ \\
Radix Ranunculi & 12 & $5.1 \pm 0.9$ & $1.29 \pm 0.21$ & $46.86 \pm 5.88$ \\
Ternati saponins & 3 & $5.6 \pm 1.2$ & $1.29 \pm 0.21$ & $57.62 \pm 6.81$ \\
& 6 & $4.3 \pm 1.2$ & $1.20 \pm 0.27$ & $31.57 \pm 6.48$ \\
Radix Ranunculi & 12 & $4.5 \pm 0.4$ & $1.20 \pm 0.27$ & $33.82 \pm 5.72$ \\
Ternati & & & & $38.17 \pm 4.07$ \\
polysaccharides & & $5.0 \pm 0.7$ & $1.20 \pm 0.27$ & \\
\hline
\end{tabular}

Radix ranunculi ternati contains relatively high amount of saponins and polysaccharides, which are complex in composition. Many studies have shown that saponins and polysaccharides both good pharmacological activities. This study found that the saponins and polysaccharides from Radix Ranunculi Ternati had significant in vitro anti-tumor effects on human gastric cancer BGC823 cells, and could improve the immune function of normal mice, however, their exact anti-tumor constituents still need further analysis.

\section{References}

1. Chinese Pharmacopoeia Commission. (2010). Pharmacopoeia of the People's Republic of China. China Medical Scien ce Press, 300.

2. Liu, L. J. , Zhang, Z. L. (2007). The Hypersound Extraction Technology of Ranunculus Ternate Radix Polyose by

3. Orthogonal Design. Journal of Henan University of Chinese Medicine, 22 (6):29-30.

4. Nicotera P, Orrenius S. (1998). The role of calcium in apoptosis. cellCalcium, 3(2-3):173-180.

5. Pang, D. X. , Zhu, F. P. Effect of Longhu Sanbaodan on Immunocyte of Tumor Bearing Mice. Chinese Journal of Integrat ed Traditional and Western Medicine on Digestion, 9 (1):29-31.

6. Shanghai Institute of Materia Medica (1983). Chinese Academy of Sciences. Extraction and Separation of Active Ingredi ent from Chinese Medicinal Herbs, second edition. Shanghai: Shanghai Scientific \& Technical Publishers. (Shanghai Inst itute of Materia Medica.

7. Svegliati B.G. (1999). The Na+/H+exchanger modu-lates the fibrogenic effect of oxidative stress in rat hepatic satel-late cells.J hepatol, 30(5):868-875.

8. Szende B, Srkalovic G, Schally A.V. (1990). Inhibitory effects of ana-logs of luteinizing hormone-releasing hormone and somatostatin on pan-creatic cansers in hamsters. Events that accompany tumor regression.Cancer, 65(10):2279-22 90 .

9. Twentyman PR. Luscombe M (1987). A study of some variables in a tetrazoliumdye(MTT) based assay for cell growt $\mathrm{h}$ and chemosen-sitivity.Br J Cancer, 56(3):279-85. 
10. Wang, A. W. , Wang, M., Yuan, J. R. (2004). The Study on Antitumor Effects In Vitro of Different Extracts in Radix ranunculus ternati. Natural Product Research and Development, 16 (6).529-531.

11. Yin, S. C., Zheng, H. C. (1993). Study Survey of Chinese Medicine Radix ranunculus ternati. Journal of Chines e Medicinal Materials, $16(11): 36-38$.

12. Yin, C. P., Fan, L. C., Zhang, L. D. (2008). The inhibiting effect of extracts in Radix ranunculus ternati on the growth of human breast cancer cells in vitro. China Journal of Hospital Pharmacy, 28 (2):93-96.

13. Zhou, Q. A., Yu, H. B. (2009). Effect of Radix ranunculus ternati Saponins on Apoptosis and the Free $\mathrm{Ca}^{2+} \mathrm{Con}^{2}$ centration in Human Colon Carcinoma LoVo Cells. Journal of Henan University of Chinese Medicine, 24 (1):29-34.

14. Zhang, Z. R. (2004). Cultural Cytology and Technique for Cell Culture. Shanghai Scientific \& Technical Publisher s, 364.

15. Zhang, X. J., Yu, H. R., Geng, D., Zou, X. (2005). Effect of Auricularia auriculajudae polysaccharide o $\mathrm{n}$ cell immunity of tumor-bearing mice. Chinese Traditional Patent Medicine, 27 (6):691-693.

16. Zhou, L., Zhang, W. , Xu, J. (1995). Effect of Active Ingredients of Radix ranunculus ternateon Induction of TNF. Acta Academiae Medicinae Sinicae, 17 (6):456-460. 